\title{
La violencia erótica del cuerpo femenino en Farabeuf o la crónica de un instante de Salvador Elizondo
}

\author{
Raúl Carrillo-Arciniega \\ College of Charleston
}

La violencia dentro de la obra del mexicano Salvador Elizondo ha sido un tema recurrente con el que ha buscado aproximarse a un afán totalizador del mundo. Esta búsqueda a partir de la violencia dentro de la novela Farabeuf o la crónica de un instante (1965) se hace presente como elemento que potencia y reconcilia las relaciones erótico-sexuales en el relato. Este trabajo tiene por objeto mostrar dicha elaboración como conciliadora erótica que, a través de las analogías, tiene lugar en la revelación del cuerpo femenino. La novela presenta como elemento fundamental una formulación de analogías ${ }^{1}$ desarrolladas en tres planos temporales, referidos en la novela como "instantes".

Las analogías como elementos lingüísticos tienen como objetivo, según Paz, elaborar "una crítica a la visión racionalista instaurada por el saber de la modernidad" (108-9). Esta crítica se manifiesta dentro del discurso poético como un mundo enigmático que está custodiado por ellas. Las analogías que se construyen en Farabeuf, además de aportar un estatus epistemológico (Shaw la califica de ser "a pesar de su erotismo [...] una novela esencialmente metafísica" [335]), abren la posibilidad de romper con un discurso lineal y temporal que resulta en la fragmentación narrativa de Farabeuf. Esta "fragmentación narrativa"

\footnotetext{
${ }^{1}$ En semiótica — según Helena Beristáin - "es la correspondencia estructural entre las partes de dos sistemas semióticos de diferente naturaleza; correlación fundada en las conexiones que se establecen entre ambos sistemas distintos, las que se descubren mediante una operación de análisis semántico que consiste en formular un razonamiento analógico (que establece la relación de analogía, o sea de semejanza entre cosas distintas)" (253).
} 
será formulada para posibilitar las analogías, que según Eduardo Becerra, "impulse[n] la acción en un intento por superar y disolver la dualidad antagónica del mundo" (41). Esta dualidad antagónica del mundo va a ser manifestada y reconciliada desde los tres "instantes" que plantea el texto de Elizondo, que son temporalmente "simultáneos". El instante introduce dos momentos más para romper desde una perspectiva espacio-temporal la linealidad y unidad tradicional de la percepción del mundo. Este rompimiento está elaborado mediante correspondencias estructurales análogas que posibilitan la mezcla y, en ocasiones, la yuxtaposición de instantes que en la novela no están explícitamente delineados. Farabeuf resulta ser la historia en tres niveles temporales de una violencia ejercida sobre un cuerpo femenino, momento que se perpetúa en la memoria de sus personajes. Esta proyección del momento se realizará en estos tres planos-instantes y será potenciada por varios elementos que hacen su aparición desde el primer plano instante.

El primero es el momento del $a q u i^{2}$ un aqui que se delimita como tiempo presente y es desde donde se hacen los desembragues temporales. ${ }^{3}$ En este aquí el protagonista, el doctor Farabeuf, llega a una casa en donde aparentemente ${ }^{4}$ se encuentran dos mujeres, una que practica un juego impreciso (tal vez el I Ching o La Ouija) vestida de negro y otra que corre hacia la ventana de un segundo piso. Esta última viste uniforme blanco de enfermera, y es llamada por el narrador "Enfermera”. Esta enfermera dibuja un garabato ilegible mientras contempla la ascensión por la escalera del doctor Farabeuf hacia una sala de operaciones clandestina en donde se realizará una intervención quirúrgica

\footnotetext{
${ }^{2}$ Utilizo el término del aquí en el sentido que Courtés se lo atribuye como elemento de la deixis: "Elementos lingüísticos que se refieren a la instancia de la enunciación y a sus coordenadas espacio-temporales, al yo-aquí-ahora [...] debe admitirse que los deícticos pueden ser tanto enuncivos como enunciativos" (387).

${ }^{3}$ Courtés define al desembrague como el acto de enunciación que consiste "en abandonar, en negar la instancia fundadora de la enunciación y en hacer surgir, a contra golpe, un enunciado cuya articulación actacial, espacial y temporal guarde como memoria, de modo negativo, la estructura misma del "ego, hic et nunc" original (368, las cursivas son suyas).

${ }^{4}$ Utilizaré las modalizaciones de incertidumbre para referirme a ésta que puebla el discurso en donde los acontecimientos están dispuestos para que la certeza sea un elemento accesorio dentro de la novela.
} 
o amatoria. En la sala de operaciones clandestina hay un espejo desde donde la Mujer contempla a la Enfermera mientras juega de espaldas a la entrada, opuesto a este espejo se encuentra una reproducción del cuadro de Tiziano Amor sagrado y amor profano. En el piso hay colocado papel periódico, fechado en 1901 en China, para que el parquet no se manche de sangre o excrecencias porque lo que, aparentemente, se realiza es un descuartizamiento quirúrgico "ritual" que culminará en un coito.

En esa misma habitación se encuentran los dos objetos que mediante analogías harán posibles los desembragues hacia los dos planos instantes restantes: del aquí que se plantea en París en el número 3 de la rue de l'Odéon se desprenderán los demás planos instantes que se evocarán en la novela. El segundo plano instante está presentado como el asesinato-sacrificio de un magnicida chino, que devendrán en mujer redentora, fechado en 1901. Farabeuf, en el papel de espía, y disfrazado de religioso, le tomará una foto y tendrá un encuentro sexual con la ahora Enfermera, también ocultando su identidad con un traje de religiosa. El tercer plano instante será evocado por un par de cartas que se encuentran dentro de un libro en el primer plano. Éstas nos llevarán a un incidente que ocurre en una playa en donde se narra un paseo en el que una Mujer se aleja corriendo de un Hombre, que súbitamente se detiene, recoge una estrella de mar, después de destruir a su paso un castillo de arena hecho por un niño. Esta estrella de mar le produce a la mujer sensaciones horribles. Ambos, el hombre y la mujer, regresan a su habitación de hotel para hacer el amor furtivamente después de contemplar la foto del supliciado chino del segundo plano instante mencionado.

Todas estas situaciones temporales tendrán un mismo valor semántico y estarán construidas con los mismos elementos. Esto es, los tres planos instantes serán absolutamente análogos, tendrán el mismo número de componentes y las mismas significaciones: habrá una reconciliación de los opuestos (vida y muerte, amor sagrado y profano, goce y violencia, orgasmo y coito, amputación y descuartizamiento) mediante la acción de la violencia como elemento que posibilita las relaciones erótico sexuales. Así, la acción que unifica análogamente los tres planos instantes es el acto carnal o coito matizado y potenciado por los actos violentos. La violencia pues, producirá su efecto sobre un cuerpo femenino. En el primer plano-instante, el espacio del cuerpo será poten- 
ciado por las relaciones de identidad entre la tortura y la cirugía que al final actuarán como un componente de placer: "Todas estas filosísimas navajas y aquellos artilugios, investidos de una crueldad necesaria a la función a la que estaban destinados, adquirirían una belleza dorada" (Elizondo 2000: 165). En ese sentido se unificará de igual modo el acto amatorio. En el segundo ocurrirán los mismos contenidos, hay un cuerpo sobre el que se ejerce la violencia, en forma de suplicio y descuartizamiento, que detona la relación sexual entre Farabeuf y la Enfermera que se entregan al acto amatorio en sus atuendos religiosos, con lo que se establece no sólo una analogía con el cuadro de Tiziano, sino con el contenido del primer plano. Por último, el tercer plano instante está marcado por la relación carnal impulsada por la foto del supliciado chino y la sensación desagradable de tener en la mano una estrella muerta, es decir, un cadáver sobre el cual se ha ejercido un contenido de violencia, aunque un tanto atenuada. En este último plano la pareja contempla la foto y evoca el día en que fue tomada.

Esta reconciliación analógica (amor sagrado vs. amor profano, erotismo vs. sexo, goce vs. violencia, eternidad vs. instante, etc.) se realiza desde la articulación del elemento del interdicto que Bataille presenta para explicar las manifestaciones del erotismo y su vinculación con un espacio sagrado. El punto que hace posible esta unión, en la perspectiva de Bataille, surge desde la conexión de dos mundos que identifica como el mundo de lo profano y el mundo de lo sagrado. Mismo espacio teórico sobre el cual está elaborada esta reconciliación de contrarios en la novela de Farabeuf. Los elementos que posibilitan entonces esta conjunción de dos mundos, en apariencia disímbolos, son el interdicto y su consecuencia en la trasgresión. Así, aunque el mundo de lo profano y el mundo de lo sagrado sean opuestos, "son dos formas complementarias" (95). El primero "es el de los interdictos" y el segundo, el de las trasgresiones (95). Bataille comenta más adelante:

Este modo de ver es difícil, en el sentido que sagrado designa al mismo tiempo los dos contrarios. De una manera fundamental, es sagrado lo que es el objeto de un interdicto. El interdicto al designar negativamente la cosa sagrada, no tiene solamente el poder de provocarnos - en el plano de la religión- un sentido de pavor y de temor. Ese sentimiento se cambia en el límite por devoción; se cambia por adoración [...]. Los hombres están al mismo tiempo sometidos a dos movi- 
mientos: de terror que rechaza, y de atracción, que rige al respeto fascinado. El interdicto y la trasgresión responden a esos dos movimientos contradictorios: el interdicto rechaza, pero la fascinación introduce la trasgresión (96).

El rechazo que se plantea para el interdicto es el de la violencia, la acción del cadáver en descomposición como testimonio fehaciente de la violencia. En Farabeuf la violencia es el elemento bajo el cual se identifica el interdicto y su trasgresión. Es el elemento que se transforma para "cambiarse en el límite" por placer; así, la violencia pasa a ser un culto ritual que se transforma en adoración y rememoración del instante cuando fue ejercida. Asimismo la distinción entre los dos espacios en que se contiene esta búsqueda de reconciliación de los contrarios en la novela de Farabeuf tiene su correlato con la introducción de esta posibilidad de reflexión en el plano figurativo ${ }^{5}$ con la inclusión de la pintura de Tiziano Amor sagrado y amor profano en el primer plano instante de la novela. Esta referencia es presentada desde un primer momento y con eso se abre un espacio conceptual para la elaboración de las analogías como una tentativa por suprimir y, así, unificar los contrarios. Los elementos que forman el cuadro tendrán su correlato en el primer plano instante. Este cuadro resume la actitud del primer plano por plantear una reconciliación: el cuadro muestra dos mujeres que son la misma, una vestida y otra desnuda, ambas sentadas sobre una misma fuente. En el centro hay un niño que hurga dentro de la fuente, este niño es mostrado como el elemento reconciliador o posibilitador de trasformar a la misma en dos potencias distintas, la misma pero diferente, la misma transformada por la acción del niño: el amor, la pasión, el deseo o, tal vez, la violencia. La pasión vista como elemento desestabilizador de los mundos en donde el interdicto invita a la trasgresión de ser la misma persona pero diferente. En el primer plano narracional hay también dos mujeres que no se define claramente si es la misma o son dos, una vestida de negro y otra de blanco,

\footnotetext{
${ }^{5}$ Con ello me refiero a lo que entiende Courtés (de la escuela greimasiana) por figurativo: "todo lo que puede estar [en un universo de discurso dado (verbal o no verbal)] directamente relacionado con uno de los cinco sentidos tradicionales: la vista, el oído, el olfato, el gusto y el tacto; en pocas palabras, todo lo que depende de la percepción del mundo exterior" (238).
} 
tal vez la misma pero trasformada. Es ahí cómo dentro de la novela se extiende esta reflexión sobre la reconciliación y la unificación de las entidades contrarias que, como Bataille comenta, son realidades en apariencia opuestas, una unificación lograda con base en interdictos que posibilitan la trasgresión a un espacio interdicto: el espacio donde los mundos se contagian por contigüidad. En la novela se lee: "De pie inmóvil, en mitad del salón te has desplazado con el deseo de ser otra, hacia el fondo del pasillo en donde inquieres siempre una misma pregunta haciendo caso omiso de ti misma; un cuerpo abandonado ante el espejo, de frente a un cuadro incomprensible, de espaldas siempre a quien te mira en esa fuga de ti misma que no admite mostrar tu rostro" (114). En este pasaje se descubren los elementos con los que Elizondo persigue la unificación de esos contrarios, que son los mismos por analogía, son emanaciones de un mismo impulso que busca negarse para así conformarse y que más adelante se irán a elaborar con la puesta en marcha de la violencia como detonante de las relaciones erótico sexuales en los tres diferentes planos instantes.

En su ensayo "De la violencia", Elizondo demarca la importancia temporal del instante así como del cuerpo humano para operar un conocimiento: "El cuerpo [...] tiene ese conocimiento inusitado que sólo es propio del cuerpo: el terror. Es por ello que la violencia como noción postula, también, al cuerpo como sujeto del mundo. Un cuerpo supliciado o violentado es un signo muy específico [...] de un testimonio que sólo es formulable en los términos de ese mismo cuerpo. La violencia es cosa de cuerpos humanos; de cuerpos que esperan lo inesperable: lo que ya pasó, lo súbito, lo que no pasará jamás. Y esta esperanza acentúa el paradójico carácter que tiene la violencia de no ser imprevista y de ser súbita a la vez, es decir, imprevisible" (1992: 5758). En este sentido la violencia prefigura el último destino del cuerpo: la muerte. La violencia es un acto iluminador que genera sensaciones de terror sobre el cuerpo; así genera un estado de permanente expectación ante la posibilidad temporal de que el cuerpo sea agredido y al mismo tiempo es una actitud reveladora: al revelar la muerte lo hace en términos de dolor, de negación de ese mismo espacio. Al negar al dolor se abre la puerta al terror sobre el cuerpo. De ese modo el espacio sobre el cual se muestra la violencia es el cuerpo, un cuerpo abierto hacia el dolor que aterroriza. 
Dentro del primer plano-instante la violencia es ejercida en el cuerpo de una mujer imprecisa y se torna como un acto ritual repetitivo en el que se hace referencia a una cirugía que presenta tintes de violencia ejercida como un asesinato ritual e instantáneo. La analogía se construye como proceso de identidad entre la acción de realizar una intervención quirúrgica con un bisturí y un acto "sagrado" que se define en la novela como "un sacrificio inconfesable":

\begin{abstract}
Alzadas [las manos] en un gesto hierático y ritual, sosteniendo en la derecha el afiladísimo bisturí que había seleccionado, Farabeuf se dirigió hacia el pasillo, con la cuchilla en lo alto: un gesto religioso inexplicable y como premonitorio de un crimen, dejando por donde iba un rastro de emanaciones de quirófano. Iba al encuentro de la Enfermera que lo aguardaba inmóvil en el fondo de aquel pozo de sombra, dispuesta a un sacrificio inconfesable (166).
\end{abstract}

El sacrificio tiende el puente analógico con el que se maximiza la violencia y se torna así la muerte en devoción superándose la violencia misma, desde la violencia. El sacrificio consagra a la víctima, y al mismo tiempo la diviniza; en palabras de Bataille: "Una violencia tan divinamente violenta eleva a la víctima por encima de un mundo plano en el que los hombres llevan su vida calculada" (115). En este sentido, la violencia se transforma en un modo de conocer debido a su "ausencia de conciencia", que según Elizondo en Cuaderno de escritura manifiesta la propia violencia: "La ausencia de conciencia que es el ámbito en el que la violencia acontece no permite ni siquiera considerarla como una experiencia sino como un contenido [...] como la expresión de un lenguaje paralógico mediante el cual la posibilidad de violencia misma se manifiesta como potencia en todas las cosas del mundo" (61). Elizondo reconoce y atribuye un componente "extrarracional" (en el sentido de estar fuera) a la formulación de la violencia. Al ser ésta un contenido tiende el puente hacia una elaboración que se encuentra fuera de los límites racionales y que proporciona un mecanismo de tipo ontológico y epistemológico. En el sacrificio se busca anular la violencia, paradójicamente, a través de la violencia y elevar así al cuerpo mutilado, o mejor, expuesto a un estadio en donde el dolor sirve de vía. Es decir, la novela de Elizondo muestra en términos de Bataille a la violencia como el mecanismo del interdicto que posibilita 
la trasgresión del cuerpo, para así reconciliar a los contrarios. Estos opuestos tratan de ser paradigmas del pensamiento y de actitudes con respecto al cuerpo que se tienen en el mundo de Occidente frente al mundo de Oriente. No es casual pues que en la novela se muestren por analogías las semejanzas que se pueden llevar a cabo entre cosas en apariencia disímbolas. Podemos encontrarlas dentro de los niveles ausentes de conciencia: los métodos de adivinación pertenecientes a "dos mundos distintos", por un lado la Ouija y por el otro el I Ching, ambos instrumentos de adivinación que están compuestos por sistemas binarios: el "si" y el "no", el "ying y el "yang”. 6 El hecho de que en la novela no se defina claramente cuál de los dos juegos es el que se practica, revela la intención de difuminar las apariencias y homologar los contenidos adivinatorios. La violencia en ese sentido es el elemento que va a funcionar como vía de trasgresión dentro del propio sistema chino de adivinación por pensamiento análogo. ${ }^{7}$ La foto del supliciado chino se convierte en un detonante erótico de las relaciones carnales que se llevan a cabo entre Farabeuf y la Enfermera en el plano instante tercero. Asimismo esta foto del descuartizamiento tiene su analogía con el ideograma chino de liú; elemento que a su vez busca reconciliar los tres elementos que potencian el desembrague a los tres planos instantes en los cuales la novela forma su dimensión espaciotemporal: la foto del supliciado, el ideograma chino proveniente del $I$ Ching, y una estrella de mar que se asemeja al ideograma, mismos elementos que van a formar y potenciar un sistema extrarracional que es el de la violencia como vehículo de la trasgresión: "Si aprendes a decir este nombre comprenderás el significado final del suplicio. [...] Es el número seis y se pronuncia liú. La disposición de los trazos que lo forman recuerda la actitud del supliciado y también la forma de una estrella de mar, ¿verdad?" (2000: 227).

\footnotetext{
${ }^{6}$ Eduardo Becerra menciona que ambos sistemas adivinatorios reflejan "la misma tentativa por superar la dualidad antitética del mundo" (41).

7 El ideograma que toma de muestra para su novela condensa el concepto del que este ensayo hablaba en palabras de Elizondo como contenido. Becerra a propósito de este ideograma dice: "el número seis [...] es asociado al triagrama ch'ien, compuesto por tres yang y que simboliza el cielo y lo creativo; simboliza también las experiencias de unicidad (hermanamiento universal) y las personas que actúan bajo su influencia suelen estar dominadas por los impulsos sexuales" (227).
} 
El espacio sobre el cual se efectúan estos reconocimientos analógicos tiene su fin último en la apropiación del cuerpo. Por estos mecanismos se busca que la reconciliación se haga a partir y como resultado de un proceso violento que unifique y reconcilie dos realidades que al final habrán de ser análogas. Es sobre el cuerpo que se irán a realizar las suertes por la apropiación tanto de los instantes como de los placeres: es decir, de las realidades analógicas que tienen como objetivo fragmentar en todo el sentido de la palabra la totalidad del discurso de Farabeuf. Al someter al cuerpo a una serie de agresiones físicas cuyos componentes recorrerán los límites de los interdictos motivados por las trasgresiones, se abrirá paso a la elevación por "fragmentación” tanto del cuerpo como de todos los niveles de la novela. Esta fragmentación está posibilitada en suma por la presencia de las analogías sobre las que trabaja Elizondo, y son parte fundamental para llevar a cabo la fragmentación del discurso en los niveles temporales llevados hasta los niveles semánticos con la mutilación-fragmentación del cuerpo.

El cuerpo es uno solo que se muestra como una superficie de expiación, un cuerpo que debe de servir para desarrollar un sacrificio, para lavar un contenido ineludible del cuerpo. Este cuerpo sobre el cual descansa toda la actividad sexual articula una vindicación de los universos fragmentados. Sobre el cuerpo femenino hay un sacrificio que eleva a la víctima a estadios altísimos y absolutamente redentores: "El sacrificio — aduce Bataille_, si es una trasgresión deliberada, es la acción voluntaria cuyo fin es el repentino cambio del ser que es su víctima" (126). Es por eso que al presentar al supliciado chino como una mujer se le atribuye, en ese sentido, un papel redentor a través de la acción de la violencia que reconcilia realidades, en apariencia, opuestas. El cuerpo femenino es violentamente acometido para liberación y continuación de todos los seres y tradiciones. Elizondo escribe a propósito de la identidad del supliciado: "El supliciado es un hombre bellísimo. En su rostro se refleja un delirio misterioso y exquisito. Su mirada justifica una hipótesis inquietante: la de que ese torturado sea una mujer" (221). Más adelante se lee: "Es una mujer. Eres tú. Ese rostro contiene todos los rostros" (222). Para finalmente declarar: "por primera vez [...] por primera vez [...] es posible sentir toda la belleza que encierra un rostro [...] sí, por supuesto [...] es una mujer [...] es una mujer bellísima [...] la mujer-cristo. [...] Es el rostro de una mujer porque sólo las mujeres resisten el dolor a tal extremo" (225). 
El cuerpo femenino como receptáculo y reconciliador de los opuestos en toda su universalidad es la gran revelación que Elizondo proporciona dentro de su elaboración del recorrido de la violencia. El cuerpo femenino resulta ser pues el espacio en donde concurren todas las fuerzas, en donde la violencia habrá de ser ejercida para funcionar como un elemento liberador y reconciliador de los opuestos universales. La particularidad sobre la que se trabaja el cuerpo es su desnudez. El cuerpo femenino es un cuerpo expuesto, es un cuerpo desnudado para sobre él revelar la carne e iniciar una expiación que conduzca no sólo al goce físico sino también a una elevación reconciliadora de todos los sistemas que busca conjuntar Elizondo dentro de su novela. La violencia ejercida sobre el cuerpo femenino tiene como resultado la muerte pero antes el lucimiento de la carne, y con él el gozo, la unificación y el restablecimiento de un orden primigenio: “Tu desnudez misma sería como la confirmación de un acto definitivo. Acaso estás muerta, allí, ante mí. No faltarán sino unos minutos para que tu cuerpo se recubra de esas estrías lentas que la sangre traza, por gravedad, en las comisuras del cuerpo después de que el bisturí recorre la piel como una caricia apenas perceptible, pero inequívoca en el florecimiento de las vísceras que brotan a través de las incisiones como los retoños de una primavera tenebrosa. No; no hables. Guarda silencio, tienes que escuchar todo lo que yo digo antes de tu desfallecimiento" (231). La elevación del cuerpo femenino a una inmolación queda manifestada con la analogía del sacrificio de la ahora mujer-cristo, la instauración de la iglesia católica en China y el ritual en el que se convierte la sala de operaciones en que se interviene un cuerpo femenino. Este contagio de sistemas de los diferentes planos instantes hace que los actos violentos se revistan de contenidos unificadores y reconciliadores específicos; actos de salvación del uno por el todo: "Ahora ya tu cuerpo es un hecho absoluto" (239). De ese modo el cuerpo posee el contenido de revelación que es "descubierto" en el sentido de quitar la cubierta por la violencia que sobre él se ejerce.

Todos los actos violentos concurren en una intervención sobre el cuerpo femenino que es ejercido como vía y vehículo para una unificación de todos los opuestos universales planteados en la novela. Las analogías, además de tener como función la reconciliación y la fragmentación de los niveles temporales, es decir, de los planos instantes que fragmentan el discurso, presentan la totalidad y funcionalidad de 
la violencia como contenido que crea una comunicación entre los elementos del mundo discursivo de Farabeuf. Estos elementos son las acciones sobre un cuerpo femenino desnudo que busca ser el espacio para el goce doloroso de una unificación que Elizondo plantea como necesaria. La violencia descubre al cuerpo femenino y lo exhibe como resultado del sistema analógico que restablece los contarios que se complementan: "Del ying al yang cuántos eones, del sí al no cuántos quizás".

\section{Bibliografía}

Bataille, Georges. El erotismo. Barcelona: Tusquets, 1988.

Beristáin, Helena. Diccionario de retórica y poética. México: Porrúa, 1992.

Courtés, Joseph. Análisis semiótico del discurso. Madrid: Gredos, 1997.

Elizondo, Salvador. Cuaderno de escritura. México: Vuelta, 1992.

—. Farabeufo la crónica de un instante. Introducción de Eduardo Becerra. Madrid: Cátedra, 2000.

Paz, Octavio. Los hijos del limo. Barcelona: Seix Barral, 1974.

Shaw, Donald L. Nueva narrativa hispanoamericana. Madrid: Cátedra, 1999. 
